\section{PILOT CHARTS.}

$\mathrm{F}$ ROM the popular and astrological point of view, meteorology is as old as the oldest of the canonical writings ; but as a scientific study it may truly be said to belong wholly to the great Victorian era of scientific development. It was only in the 'thirties of last century that Redfield and Reid-the former in America, the latter in the West Indies - set about the patient study of the vagaries of storms, and discovered that these meteors were, like everything else in Nature, subject to natural laws. By the middle of the nineteenth century the progress made by the early pioneers was such that Maury felt justified in utilising the results in the preparation of his pilot charts for mariners all the world over. Maury's charts were certainly not perfect; fifty years afterwards many would, no doubt, regard them as a confused mass of information which would weary the most persistent student in an endeavour to unravel them; but useless as they seemed to be at first sight, they have proved to be the pioneers of the most useful works published in the interest of navigators. It has long been recognised that the sailor wants, in addition to ponderous tomes dealing minutely with every phase of navigation, handy summaries of the more essential features of everyday life on the ocean, arranged in a simple manner for immediate reference. The Board of Trade published charts containing varied information forty-five years ago, and the Hydrographic Department issued its well-known quarterly pilot charts more than thirty years ago. Other nations, France, Holland, Denmark, \&c., have devoted much attention to the necessity of keeping mariners acquainted with all the latest information relating to the meteorology of the various oceans. For many years past the Hydrographic Department at Washington has left no stone unturned to popularise its Pilot Chart of the North Atlantic, and of late years it has been perfecting a similar work for the North Pacific. In the meantime, Germany has not only been increasing her naval strength, but her mercantile fleet is daily becoming more and more important, and the latest evidence of this is found in the January number of the Annalen der Hydrographie und Maritimen Meteorologie, in which Dr. Neumayer announces the issue, by the Deutsche Seewarte at Hamburg, of a monthly chart for the Atlantic, mainly for the steamships engaged in the Transatlantic trade.

But the importance of the question of keeping the mariner in touch with the progress of meteorology has not escaped the attention of the English authorities, for the Meteorological Council has just distributed a specimen monthly pilot chart of the North Atlantic and Mediterranean for the month of January, it having been decided to commence a series of such publications in April. In the compilation of the charts, advantage is to be taken not only of information in the possession of our own Hydrographic and Meteorological Offices, but also of any suitable facts published by similar establishments in other countries. Just as we are certain that the atmospheric conditions during winter are different in various ways from those which obtain in summer, so we may conclude that between the extremes there are, on the average, more or less gradual changes in the controlling features, and, therefore, we must expect that every month in the year has its own individualities, which are not exactly in agreement with even those of neighbouring months. To be of real use to the navigator, then, information should, as far as possible, be sorted out into its principal monthly features, and this is to be the aim of the Marine Department of the Meteorological Office under Commander Hepworth, R.N.R., the superintendent. Each ocean area of $5^{\circ}$ of latitude by $5^{\circ}$ of longitude contains a wind-rose showing the prevailing winds, some of the less frequent winds, and the frequency of calms, a simple method being adopted to indicate the mean strength of the wind, whether light, moderate, or gale. The normal limits of the Trades; the sailing routes recommended to and from the Equator; the steamship routes to and from America; the mean paths followed by cyclonic areas ; the region in which gales exceed Io per cent. of the wind observations; the localities affected by fog; and the ice limits about Newfoundland are laid down. A feature of as great interest to the theoretical physicist as to the practical sailor will be the ocean currents for each separate month, based upon observations covering a period of sixty-five years. Until the Admiralty and Meteorological Office recently published a selection of the currents in representative months, the scientific world had to be content with studying the circulation of the waters from a chart representing the annual results only. There will now be an opportunity for a much closer study, as the monthly winds and currents are given together in the same sea-room, while the distribution of atmospheric pressure for the same month is given, with that of the air and of the sea temperature, in an inset chart, and all three subjects must be considered as inseparable when investigating ocean currents. Two other inset charts represent south-westerly and westerly types of weather over Western Europe. In addition to the foregoing pictorial method of displaying the facts, a considerable amount of valuable information is conveyed in descriptive letterpress on all available spaces, directing the navigator's attention to the dangers associated with making the Spanish coast, to the Harmattan winds of West Africa, the Northers of the Gulf of Mexico, the Mediterranean sirocco and other winds; to treacherous inshore currents ; to the difficulties arising from the lowlying haze and the great refraction along the west coast of Africa ; to the rollers breaking on the South American coast, from Trinidad to Guiana; and advice is given as to the best routes for crossing the Equator. An interesting article is devoted to Atlantic storm systems, showing how the mariner must combine his wind and barometer observations when he wants to ascertain the behaviour of the disturbance which may be affecting his ship, the problem being much more complicated than is generally supposed, and more particularly in this age of swift steanships, which may be travelling faster than a cyclone, so that the experiences on a liner travelling eastward through a storm would be largely different from those on another meeting it going westward. Everything depends upon the particular circumstances, and with the aid of these notes and an intelligent interpretation of them, officers should be able to have a much better knowledge of the cyclonic areas through which they so frequently have to steer. For many reasons, the new pilot charts deserve to have a long and successful career.

\section{MALARIA AND ITS PREVENTION.}

SINCE the work of Laveran (I880) proved malaria to $S$ be a fever causea by the invasion of the blood by minute animal organisms, steady progress has been made in the work of probing and elucidating the etiology and pathology of this dreadful scourge.

The extent of its ravages was - and, unfortunately, still is-appalling, and the recognition of this fact has impelled many eminent scientific men to direct their best efforts towards solving the problems which have been facing us for the last twenty years, and which were the natural offspring of Laveran's discoveries.

English, Italian and German workers have competed with each other in the race and shown unprecedented keenness and enthusiasm; of their work an immense bibliography remains as a monument to-day. In America, too, has been done some of the very best work.

No. 1638 , vOL. 63] 